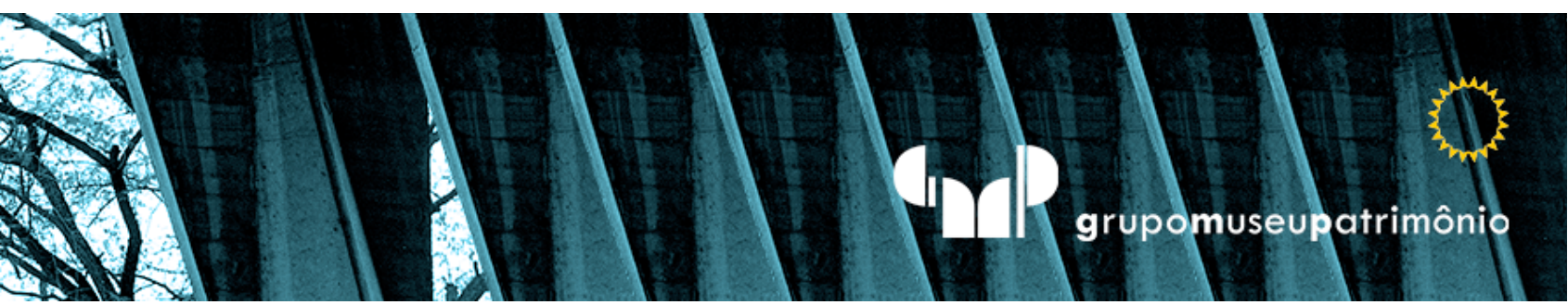

\title{
O desamparo do espectador nos projetos de Peter Eisenman da década de 1960
}

\author{
La indefensa del espectador en los proyectos \\ de Peter Eisenman \\ de los años 1960
}

\section{The spectator's helplessness in Peter Eisenman's 1960's projects}

\section{Bruno Juliani Mentone}

Mestre pela Faculdade de Arquitetura e Urbanismo da Universidade de São Paulo, São Paulo, Brasil. bruno.mentone.arq@gmail.com 


\title{
Resumo
}

Leitura do início da carreira de Peter Eisenman, entre 1967 e 1978, a partir de Michael Hays e Hal Foster analisando reinscrição que o arquiteto opera da abstração moderna. Verificou-se como isso influencia a relação com o espectador, com potencial transformador deste, condição lida a partir do desamparo como discutido por Vladimir Safatle.

Palavras-Chave: Eisenman, Peter D., 1932. Arquitetura pós-moderna. Formalismo (Arte). Teoria da arquitetura. Biopolítica.

\section{Resumen}

Lectura del inicio de la carrera de Peter Eisenman, entre 1967 y 1978, desde Michael Hays y Hal Foster analizando la reinscripción que el arquitecto opera de la abstracción moderna. Se verificó cómo esto influye en la relación con el espectador, con potencial transformador de este, condición leída desde la indefensa como lo discutió Vladimir Safatle.

Palavras-Clave: Eisenman, Peter D., 1932. Arquitectura posmoderna. Formalismo (Arte). Teoría de la arquitectura. Biopolítica.

\begin{abstract}
Reading of the beginning of Peter Eisenman's career, between 1967 and 1978, from Michael Hays and Hal Foster analyzing the architect's reinscription of modern abstraction. Founding how this influencesthe relationship with the viewer, with its transforming potential, a condition read from the helplessness as discussed by Vladimir Safatle.
\end{abstract}

Keywords: Eisenman, Peter D., 1932. Post Modern Architecture. Formalism (art). Architecture theory. Biopolitics. 


\section{INTRODUÇÃO ${ }^{1}$}

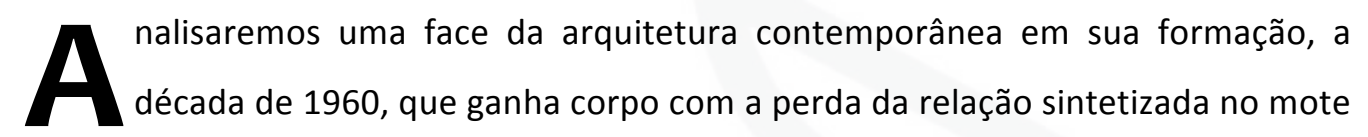
da arquitetura moderna: "forma segue função". Reconhecendo a pluralidade do momento, não é um diagnóstico totalizante, mas a leitura de um fenômeno cujas formas aparecem em arquitetos que discutem a autonomia da arquitetura. É um afastamento da linguagem arquitetônica de outras esferas, uma obstrução à tradução entre o campo da forma e o campo da função, que indicará abertura para ressignificação do espectador do projeto arquitetônico. Para tal, analisaremos Peter Eisenman a partir de sua arquitetura autorreferente. Sua profícua publicação de projetos e textos desde o início de sua atuação, com tese defendida em 1963, e primeiro projeto, House I, em 1967, favorecem essa análise.

\footnotetext{
${ }^{1}$ Este trabalho prossegue pesquisa iniciada em artigo para a disciplina FLF5241 - Teoria das Ciências Humanas (Revolução Política, Instauração Estética: arqueologia do tempo histórico em ruptura) do $2^{\circ}$ semestre de 2018 e ao memorial de qualificação apresentado em 18 de abril de 2019 durante a obtenção do título de mestre pela FAU-USP.
} 
A partir de Michael Hays e Hal Foster, compreenderemos a atuação de Eisenman marcada como produção de imagens. Sondaremos o início da carreira do arquiteto a partir desse aspecto, com objetivo de explorar características que levam a esse diagnóstico. Assim, mobilizaremos a compreensão da década de 1960 elaborada por Fredric Jameson, filósofo lido por Hays, a qual coincide com o início da carreira de Eisenman. Essa década é a transição entre o moderno e o pós-moderno, portanto o encerramento de um e formação do outro. Compreendendo o pós-moderno não como ruptura "após o moderno", mas em relação ao moderno, guardando suas próprias características e potencialidades.

A atuação de Eisenman durante o período permitirá confirmar os diagnósticos de Hays e Foster e compreender operação concomitante, a abstração que opera no espectador que se coloca frente ao objeto arquitetônico. Disso emergirá uma face complementar à questão do arquiteto ser produtor de imagens, passível de ser explorada com o diagrama do olhar de Lacan. Lido tanto por Foster quanto por Hays, o diagrama pressupõe troca de olhares entre o sujeito e o real, mediada por um anteparo-imagem. O real, o outro para o sujeito, é visto em Hays como a história encarnada na cidade, que, como manifestação das condições materiais de existência, seria a expressão do real. Compreenderemos que a cidade como forma de determinação de significados, delimitadora de formas de vida, ocupa papel específico, inscrito no tecido de significados vigente, portanto não como real, mas como anteparo-imagem.

A leitura de Foster da arte e arquitetura contemporâneas a partir de contradições, de tensões entre o real e a imagem, traduzida na dialética entre pop e minimalismo, respectivamente, auxiliará a compreender a localização do espectador como real e da cidade como simbólico no anteparo-imagem, adotando a perspectiva do arquiteto como sujeito. Posição do espectador é consequência da tentativa de Eisenman de recuperar a abstração moderna. Se no moderno a abstração operou sobre a forma deslocando-a da história, da representação, enquanto o sujeito moderno era delimitado pela ideia de sociedade moderna, pela utopia, Eisenman a reinscreve operando no espectador, o qual se torna inapreensível no processo de elaboração formal. Sua forma produtora de imagens é autorreferente, opera sobre si; no 
diagrama de Lacan, é o reforço do anteparo-imagem, circunscrita, portanto, ao sujeito e ao anteparo.

Identificaremos essa produção de Eisenman como dual, prenhe de uma contradição: por um lado, produz imagens, face ditada pelo capital; por outro, intercepta a influência deste sobre o sujeito ao deslocá-lo. Compromete o produtor enquanto despossui o espectador. Condição que torna o usuário não traduzível à arquitetura. A formação de uma linguagem arquitetônica autônoma (uma das forças motrizes da década de 1960) implica uma linguagem que não compartilha termos com a linguagem do social. Compreendendo a partir de Safatle que a formação de um sujeito livre traz possibilidade de mudança, o desamparo do usuário ao não ser predicado pela arquitetura permite o vislumbre dele como sujeito revolucionário. Se esta arquitetura, formalmente próxima ao atual estágio do capitalismo, não consegue - ou mesmo não deseja - dar voz ao corpo social contemporâneo (corpo multiforme, plural), ao menos minimiza sua colonização desse corpo ao não o predicar. Situação que permite abertura à emergência de novos sentidos ao espectador frente ao projeto.

\section{DÉCADA DE 1960}

Fredric Jameson expõe a década de 1960 como período de transição: a derrocada do moderno e a formação do pós-moderno. Compreendida em sentido expandido, o autor a delimita entre 1967 e 1975, época marcada por diferentes mudanças - crise do petróleo, Revolução Cultural Chinesa, fim da Guerra do Vietnã, Maio de 1968 que refletem o fim de um estágio do capitalismo e o advento de seu terceiro estágio, caracterizado pela colonização da cultura pelo capital. Como transição, a infraestrutura é reformulada, liberando a superestrutura, como a arquitetura, favorecendo sua autonomia. Consolidada a reformulação, retorna a superestrutura a ser reflexo da infraestrutura:

[...] num primeiro momento a reificação "liberou" o Signo de seu referente [...]. Num segundo momento, ela continua seu trabalho de dissolução, penetrando no interior do próprio Signo e liberando o Significante do Significado, ou do próprio sentido. [...] um anônimo jogo de signos torna-se impossível quando esse 
derradeiro referente a que o balão da mente estava atado é definitivamente cortado. O esfacelamento do Signo em pleno ar determina a queda numa realidade social agora absolutamente fragmentada e anárquica; os cacos da linguagem (os Significantes puros) agora recaem de volta no mundo, como tantas outras peças de sucata, em meio a todos os outros aparelhos e construções enferrujados e obsoletos que atravancam a paisagem-mercadoria e se alastram pela "cidade colagem", a "delirante New York" de um capitalismo avançado pósmodernista em plena crise. (JAMESON, 1992, p.113-115)

O autor define a história como a sucessão de períodos marcados por dialéticas que operam contradições contidas no presente (JAMESON, 1998). Uma característica do pós-moderno é reflexo da perda da compreensão desse desenvolvimento do tempo. O moderno abarca o tempo a partir de metanarrativas, uma unidade; o pós-moderno é fragmentário, tempo feito de momentos sucessivos (JAMESON, 1996). A perda do sentido de história reflete na predominância da superficialidade, achatamento dos produtos culturais. A década de 1960 situa-se entre a perda das metanarrativas e a instauração de pequenas narrativas.

Cada fase do capitalismo é marcada por uma condição de produção, uma infraestrutura, refletida em uma formação característica, uma "dominante cultural" que irradia sobre as formas em decadência ou resistência. O pós-moderno é expressão do terceiro estágio do capitalismo, marcado pelo protagonismo dos EUA, cujo papel de colonizador, por meio da cultura, intensifica sua irradiação (JAMESON, 1998). Jameson denomina esse interregno entre o moderno e o pós-moderno de tardo-moderno (late modern); Hays, de tardo-vanguarda (late avant-garde). A "flutuação do Signo", o significante liberado do significado, leva a um momento propício, a explorar questões próprias à disciplina, consequentemente durante essa década há diversos impulsos sobre a autonomia do campo: Eisenman com sua linguagem autorreferente às formas, Rossi e a permanência do tipo, Venturi e a linguagem da strip, por exemplo. Venturi expressa o pós-moderno em ascensão, Eisenman e Rossi são expoentes da decadência do moderno. Estes levam adiante a linguagem moderna, mas acusam sua insuficiência, como expressão que não terá mais espaço no novo estágio do capitalismo, marcado por uma arquitetura reificada, 
um conjunto de estratégias, de subsistemas formando uma "Nova York delirante", arquitetura como prática gerencial, tecnocrata (HAYS, 2010, p.166-169).

A mudança infraestrutural da década de 1960 é concomitante à transição de centralidade da Europa para os EUA a partir do fim da Segunda Guerra. A transição favoreceu a noção de autonomia, visto que nos EUA não há o mesmo contexto para aproximar arte e vida das vanguardas modernas. A Segunda Guerra mostrou problemas na aposta que se fazia à racionalidade (ARGAN, 2014), decreta-se o fim da história. Movimentos modernos começam a ser lidos como encerrados (FOSTER, 2017a). Se para a Europa havia uma sociedade a construir:

[...] nos Estados Unidos é assumido que a revolução já ocorreu em 1776, e considerou-se que iniciou uma ordem social que não seria substituída por desenvolvimentos subsequentes. [...] o tema revolucionário nunca foi um aspecto muito proeminente na especulação americana sobre edifícios. (ROWE, 1975, p.4, tradução nossa)

Como se a ideia de revolução que motivou as vanguardas europeias no século XX já houvesse ocorrido nos EUA, bastando aflorar e irradiar esse desenvolvimento. $O$ social estaria dado, reorganizando-se não a partir de uma ruptura, mas de evolução, continuidade do modo de produção. Situação que favorece a autonomia do estético no sentido de independência, de dar sua própria lei; diferente do desejo de produzir a sociedade, é meio de preservar o sujeito produtor. Afrouxada a ligação com o meio social, transita da produção de objetos à produção de imagens (HAYS, 2010; BURGER, 2008).

Hays aproxima essas transições, de tempo e contexto, a uma crise da cidade. Para ele, essa crise, explícita na década de 1960, é o declínio da forma que vigorava desde o Renascimento e instauração de uma nova. Giulio Carlo Argan (2014) ao discutir arquitetura nos anos 60 aponta crise semelhante: distinção entre a cidade tradicional, contexto do projeto, o modelo de cidade ao qual o projeto moderno remete, e a cidade de massas, do fluxo de informações, contexto da programação. Entendendo a cidade como produto cultural do qual a arquitetura participa, essa 
leitura permite-nos ver a cidade tradicional como um todo orgânico ${ }^{2}$ que estrutura vínculo entre vida social, trabalho e artes, como a arquitetura. Por sua vez, a cidade do terceiro estágio do capitalismo, do fluxo do capital financeiro, gera um palimpsesto, um conjunto de fluxos que se organizam e reorganizam de forma parcial. Forma um conjunto apenas no sentido do todo que permite compreender a fragmentação (BURGER, 2008), ou como Jameson (1996) coloca, cidade fragmentada em pequenos conjuntos fechados e justapostos, como o hotel Bonaventure, exemplo pós-moderno. A ideia de relação orgânica entre diferentes esferas, a procura por vínculo entre arte e vida, cidade e uso, enfraquece (HAYS, 2010; BURGER, 2008). É a concretização da pretensão moderna não realizada de:

$$
\begin{aligned}
& \text { [perda dos] critérios para a racionalização e para a produção do } \\
& \text { sentido socialmente partilhados. Isso significa que a } \\
& \text { substancialidade que outrora enraizava os sujeitos em contextos } \\
& \text { sociais aparentemente não problemáticos estaria } \\
& \text { fundamentalmente perdida. (SAFATLE, 2016, p.57) }
\end{aligned}
$$

Se por um lado essa condição direciona a discussão da arquitetura à própria instituição, por outro, possibilita a "afirmação do desamparo como afeto social" (SAFATLE, 2016, p.57).

\section{EISENMAN DURANTE A DÉCADA DE 1960}

Ao analisarmos textos de Eisenman dos anos de 1960 e 1970, e a série de casas, da House I, 1967, à House $X, 1975$, percebemos que esse conjunto coincide com a década de 1960 de Jameson. Esses projetos, denominados de Transformações, ou

\footnotetext{
2 "Em sentido geral, a obra de arte pode ser definida como unidade do geral e do particular. [...] Na obra de arte orgânica (simbólica), a unidade do geral e do particular é estabelecida sem mediação; na obra não orgânica (alegórica), ao contrário - é o caso das obras de vanguarda -, trata-se de uma unidade mediada. Aqui, o momento da unidade é, por assim dizer, afastado para infinitamente longe; em caso extremo, não é produzido, afinal, senão pelo receptor. [...] A obra de vanguarda não nega a unidade como tal (por mais que os dadaístas tenham intencionado coisa semelhante), mas um determinado tipo de unidade, a relação entre a parte e o todo que caracteriza a obra de arte orgânica" (BURGER, 2008, p.106).

A obra orgânica é aquela que transmite a ideia de um todo no qual todas as partes são necessárias e suficientes, a impressão de uma unidade imanente entre o todo e as partes, diferente da composição paratática, que depende de um mediador, como o espectador, para formar sua unidade.
} 
diagramas de interioridade, são um mergulho na arquitetura autônoma por meio da forma autorreferente, análogo ao voo do signo descrito por Jameson.

Comparando sua tese, The Formal Basis of Modern Architecture, de 1963, e texto de 1969 sobre a House I (EISENMAN, 1975), vemos o distanciamento do social. Na tese, o papel do arquiteto é articular a forma com objetivo de organizar um ambiente distendido para clareza do sujeito que o frequenta (EISENMAN, 2006). No texto, amparado pela gramática gerativa de Noam Chomsky, a forma é produto da relação entre a estrutura profunda, imanente ao objeto, e a estrutura aparente, o que é perceptível. O papel do usuário passa a ser observar e compreender as relações da forma. Ele é externado, reduzido a um olho que percorre o objeto (EISENMAN, 1970, 1975, 2004 e 2006). Diferentes desenhos desta série de casas não apresentam referência ao usuário, como uma escala humana, ou ao entorno. A House IV é apresentada como um curta mostrando o cubo isolado se transformando na forma final. A House VI é desenvolvida a partir de um percurso que subjaz à forma, mas que não aparece na forma final (IZAR, 2015), o espectador desaparece. A percepção deste trajeto só é acessível pelos diagramas elaborados por Eisenman no desenvolvimento da casa. São "[...] formulações dentro das quais o homem vai se convertendo em um elemento secundário." (MONTANER, 2001, p.168), condição que leva a leituras de Eisenman como elitista, hermético (JENCKS, 1989). Em sua série de casas, bem como textos do período, o signo torna-se autônomo e dobrado sobre si, autorreferente, rompe a relação entre forma e usuário presente na tese.

Análogo ao voo do signo exposto por Jameson, ao fim da década de 1960, quando Eisenman parte da série de casas para as Decomposições, as "cidades das escavações artificiais" $^{3}$, o signo "cai". Já não há o todo anterior, a relação com a cidade fragmentada não guarda a mesma unidade que a composição orgânica, é uma construção parcial, mediada por quem produz. Cannaregio, de 1978, projeto para a região de Veneza, não é feito sobre o local, mas sobre o projeto de Le Corbusier para

\footnotetext{
${ }^{3}$ Nome dado por Eisenman à sua segunda fase, na qual "[...] assistiremos a um modo peculiar de aproximar-se do lugar que muitas vezes leva a uma interpretação artificiosa deste ou, em casos extremos, à invenção completa do terreno onde se atua" (MONEO, 1999, p.158-159).
} 
o local (HAYS, 2010). Quando tenta aproximar-se da cidade, a forma é direcionada à instituição arquitetura. Sem a coesão da cidade moderna, o projeto também é fragmentado, composto de diferentes sobreposições: o projeto de Le Corbusier, referências arbitrárias a Veneza, e repetições da House XIa.

Concomitantemente, Eisenman percorre o declínio do moderno, buscando inicialmente corrigi-lo. Em sua tese, procura resgatar a forma como meio de corrigir o desequilíbrio dela em relação à técnica e à função (EISENMAN, 2006); a representação, o semântico, está presente, apenas não é o foco. Durante as Transformações, passa a remover da arquitetura a dimensão semântica, que denomina de culturalmente condicionado, em nome de relações, o sintático. Para tal, será caro a Eisenman a abstração, a qual identifica como uma ferramenta moderna (EISENMAN, 1971). Ele a utiliza como meio de desvincular as formas de sentidos prédeterminados, remetendo-a a suas próprias relações; arquitetura de relações ao invés de representações. $O$ arquiteto busca o conceitual, o conceito de casa não é o conceitual da arquitetura, mas do habitar. Conceitual, como estrutura de relações, é a arquitetura de arquitetura (EISENMAN, 2004). A diferença entre operar em termos semânticos em comparação a sintáticos é que os primeiros são a partir de elementos codificados, enquanto os segundos são não codificados, relacionais. Como uma progressão da abstração, Eisenman compreende Le Corbusier operando com estrutura profunda sintática, mas a partir de uma estrutura aparente semântica, a metáfora por meio do "Estilo Internacional"; já Terragni estaria trabalhando ambas as estruturas em termos sintáticos (EISENMAN, 1970); assim, Eisenman se identifica como passo adiante, uma continuidade ao moderno.

A abstração em Eisenman pode ser compreendida por sua categoria de marks (EISENMAN, 2014). Conceito é elemento mínimo que aparece em sua série de casas, traduzido livremente como marcas. Aproveitando a pluralidade de significados do termo, remete e traduz diferentes elementos entre si: marcas de desenho, marcas como referências no projeto, marcas dos diagramas de Le Corbusier ou Terragni, marcas que um grid faz sobre outro, ou marcas físicas no edifício, passam a ter valor comum na forma. As marcas indicam operação de reificação, pois ao traduzirem descaracterizam diferentes instâncias, intersecções, 
a um mesmo valor interno ao projeto, interno à instituição arquitetônica, rompendo a relação com elementos externos: o "divórcio absoluto da forma a toda referência a materialidade, uso e associação" (HAYS, 2010, p.55) ${ }^{4}$. As marcas são transformadas, repetidas, operadas sem vínculo ou objetivo externo, mas umas sobre as outras, autorreferentes. Eisenman ataca o semântico: impede a codificação com elementos externos, a representação, ao saturar de elementos voltados à instituição; pela repetição, desestabiliza vínculo com sentido em favor da relação entre marcas, elementos não codificados.

A partir de sua segunda fase, a das Decomposições, ou diagramas de exterioridade, advoga a superação do moderno. Alinhado à década de 1960 e à crise da cidade, isso ocorre entre o projeto da House $X$ (último da série de casas apartadas do meio) e do Cannaregio (quando retoma a perspectiva de inserção em um meio), entre 1975 e 1978. É quando Eisenman (1996) compreende que a cidade moderna participa de um movimento que data do Renascimento, condicionada às noções de função, composição e história, as quais mantêm a arquitetura como representativa. A arquitetura moderna ainda guardaria uma relação orgânica com a cidade: através da exortação à função, representa a cidade moderna, da fábrica. Desse modo, a arquitetura moderna ainda não seria moderna. A abstração, associada à repetição, ganha papel não de prosseguir um projeto moderno, mas de o executar, portanto, de superar o que era feito até então.

Quanto à retomada, continuidade em relação ao moderno, Foster permite que vejamos nuances entre a perspectiva de Jameson e Hays sobre a transição entre o moderno e o pós-moderno, que, apesar de formalmente similares, possuem diferenças infraestruturais. Foster compreende a produção moderna e pós-moderna a partir de duas categorias homônimas a vanguardas: minimalismo, voltado à matéria, ao real, e o pop, vinculado à imagem (FOSTER, 2017b). Apesar de diagnosticar que o minimalismo é suprimido enquanto o pop adquire predominância, para além da noção de transição, estas categorias ensejam continuidade, implicam uma dialética vinda do moderno e ainda presente. Seguindo esse ponto de vista, a

\footnotetext{
${ }^{4}$ Hays alinha essa operação à chave modernista de desfamiliarização, como Loos e Brecht.
} 
operação de Eisenman sobre a abstração não é só um canto do cisne moderno, mas um processo, uma expressão de neovanguarda. É a retomada de tópicos do modernismo, das vanguardas, a partir das contingências da década de 1960 (FOSTER, 2017a), é a reinscrição da abstração a partir do novo contexto.

Eisenman, então, não repete apenas elementos do projeto, mas também estratégias. Como suas formas, como as marcas, a abstração moderna é repetida e reinscrita, semelhante à estrutura do trauma, uma segunda ocorrência para inscrição no simbólico de algo reprimido no primeiro momento. $\mathrm{O}$ amortecimento do choque nas neovanguardas (BURGER, 2008) fornece indício do que é inscrito nessa repetição. $O$ choque do espectador diante das formas modernas atesta a não inserção destas no simbólico; o que o autor chama de institucionalização das neovanguardas seria a inscrição dessas formas no simbólico, passam a fazer parte dos códigos disponíveis. Se num primeiro momento, no moderno, a forma é deslocada da história da disciplina, não é deslocada a maneira de operar a forma, a representação. Quando Eisenman ataca a representação buscando a eclosão de novos sentidos, é abstraído (no sentido de destacar, afastar, puxar para fora) como efeito colateral o espectador, elemento necessário à representação moderna da função. O espectador é deslocado da formulação do objeto arquitetônico, sem seu significado associado à função, eclode como significante vazio. Se os primeiros projetos da série de casas repetem formas modernas, como a House I repete a Casa del Fascio de Terragni, ao fim da série, a House $X$, repete formas da própria série $^{5}$. Repetição autorreferente da qual emerge o significante vazio, o signo flutuante. Diagramas que não remetem à função, à cidade, mas uns aos outros, autorreferentes que ensejam um vazio, como o vazio central recorrente em projetos de Eisenman (DAVIDSON, 2006), ou o vazio da forma "El", cubo com cubo

\footnotetext{
${ }^{5}$ A autorreferência de Eisenman não é compreendida como um processo fechado a cada projeto, mas à disciplina. Por mais que ao longo da série de casas o arquiteto forme uma cadeia de citações de projetos próprios, há referências a outros arquitetos. Não desconsidera a história da arquitetura, que denomina de diagramas de anterioridade, "o conhecimento acumulado de toda arquitetura prévia" (EISENMAN, 1999, p.37, tradução nossa). Como exemplo, é possível ler na House I referência a outros arquitetos, como Aalto e Wright, além de Le Corbusier e Terragni (MENTONE, 2020), os quais aparecerão também em projetos posteriores.
} 
menor subtraído (forma irredutível e elemento formal base de projetos em sua série de casas).

Repetição de caráter melancólico, vazio como falta, visa o retorno a um estado passado, não supera a perda da cidade moderna (HAYS, 2010), como a busca no projeto do Cannaregio por alguma cidade. Cidade moderna como unidade, sem ela, curto-circuitada a representação, o semântico da arquitetura, as formas autorreferentes erram, flutuam. Buscando preencher esse vazio, a resposta de Eisenman é autorreferente à instituição, compondo um intricado nexo entre projetos e textos, por exemplo. O texto tem um aspecto de compensação, de tal forma "necessário" para estabilizar a leitura da forma, pois, como diz Evans (1985), para compreender Eisenman é necessário aceitar sua narrativa formal, o texto protege a intenção do arquiteto. A linha que procurava conectar a arquitetura à sociedade dobra conectando a arquitetura a si mesma, forma a arquitetura conceitual de Eisenman, arquitetura sobre arquitetura, arquitetura de imagens.

A perda da função rompe a unidade não mediada, orgânica. A cidade moderna, como expressão que marca a relação orgânica do produtor com o outro, acusa em sua crise o vazio pela ausência do outro. A dimensão do projeto, a forma arquitetônica, estagna em uma imagem do passado, do período moderno, impasse que a desassocia da vida:

[...] a arquitetura da casa pré-fabricada, muitas vezes com alguns móveis integrados, perdeu muito da comunicabilidade de outrora: seu ambiente é sem cor e uniforme, quem ali mora sabe que é igual nos apartamentos adjacentes, no andar de cima ou de baixo do seu. Cabe a cada inquilino dar-lhe algum caráter ou tom [...] Os objetos variam e personalizam o ambiente amorfo da casa, como uma echarpe ou uma gravata personalizam a roupa em série. (ARGAN, 2014, p.274)

Entretanto, condizente com a busca de Eisenman (1970, 1971 e 1975) por novos sentidos, esse processo possibilita a eclosão de novas e diferentes formas de sensibilidade. A abstração desassocia a forma de representações sedimentadas. 


\section{DIAGRAMA DO OLHAR, SUJEITO DESAMPARADO}

A leitura de Eisenman permitiu identificar uma disjunção entre produtor e receptor, reflexo do afastamento entre o campo da arquitetura e o social. A partir das leituras do diagrama lacaniano do olhar desenvolvidas por Hays (2010) e Foster (2017a), podemos aprofundar essa formulação. Esse diagrama apresenta o sujeito e o real (o outro) entreolhando-se mediados pelo anteparo-imagem. $O$ anteparo concentra as estruturas simbólicas que permitem ao sujeito apreender o real. O olhar do real é insuportável pelo sujeito, o anteparo-imagem é mediador simbólico indispensável (FOSTER, 2017a).

Foster diagnostica que vivemos em um momento de concentração na imagem, de predominância do pop, mas com o minimalismo latente, sintoma do real afastado do simbólico. Podemos descrever o caminho de Eisenman de abstração do espectador o outro do sujeito produtor - como do real tornando-se de difícil inscrição; a abstração expurga o usuário do simbólico da arquitetura. A autorreferência de sua arquitetura e sua tradução do espectador, que passa de alteridade a elemento de projeto, a uma marca, são fatores que tornam seus projetos incapazes de apreender o usuário. Com o usuário despossuído pelo processo, o anteparo-imagem, o simbólico, é construído sem a presença dele (SAFATLE, 2016): “O deslocamento da práxis vital [...] transforma-se, então, em seu conteúdo" (BURGER, 2008, p.94).

O vazio da estrutura, o esvaziamento da dimensão semântica, permite a associação do processo de produção à forma de reprodução do capital (SAFATLE, 2016). A repetição autorreferente não incorpora o sujeito social, mas incorpora, por mimese, a forma da produção da máquina (FOSTER, 2017b), da produção em série (HAYS, 2010). Imitação que opera como interrupção e compensação ao real, objeto é simulacro do processo de reprodução do capital, que reinsere o objeto na vida como mercadoria, operação de reificação (HAYS, 2010). Eisenman difere do que critica no moderno, não faz uma arquitetura que representa a sociedade da máquina, mas uma arquitetura que opera, que é projetada, como uma máquina de imagens.

Hays situa a cidade, como materialização da história, como o real da arquitetura, mas a dialética de Foster permite a apreendermos como o anteparo-imagem. A cidade 
pós-moderna está transformada, é fragmentária, mas não ausente. A repetição autorreferente, bem como a produção pop de imagens, reforça o anteparo-imagem fragmentado, preenche os espaços para tapar os buracos, "trou", evitar o "trouma" de ver e ser visto pelo real (FOSTER, 2017a, p.130-131). A repetição de pilares, vigas, diagramas -diferentes marcas - reforça o anteparo-imagem. Conforme análise de Foster de que vivemos em período de reforço do anteparo e repressão do real, a cidade não estaria longe da produção de imagens, no real, mas - como produto cultural, como produto da arquitetura autorreferente - participa do reforço do anteparo fragmentado.

Pela forma que Eisenman ataca a representação: “[...] a repetição, a (re)produção de simulacros, tende a subverter a representação, a enfraquecer sua lógica referencial" (FOSTER, 2017a, p.75), a repetição de imagens que encobrem o real produz simulacro (HAYS, 2010) - anteparo-imagem denso rebate o olhar do sujeito como se fosse o real, que permanece latente. Hays aponta uma face crítica ao incorporar a lógica da produção à reprodução de si: enquanto (re)produz-se pela forma da produção em massa, e reifica-se como mercadoria, acusa de forma indireta a estrutura do social, a colonização de esferas pela lógica do capital.

Esta releitura do diagrama posiciona o usuário abstraído. Se no diagrama temos como sujeito o produtor e o anteparo-imagem como as construções simbólicas - seja projeto, seja cidade -, o real, o outro, é o espectador, o usuário. Independentemente do quanto a repetição autorreferente dobre a instituição sobre si mesma, o objeto arquitetônico não se desvincula de ter relação com usuário. Os projetos trazerem o espectador traduzido como marca, como simulacro, é insuficiente, há algo dele que escapa, o real latente.

O usuário abstraído por Eisenman age como reprimido; a abstração, ao não o definir, não o determinar, o desampara. O projeto autorreferente torna-se sujeito de si. Corpo autorreferente esvaziado ao ponto de a instituição arquitetura ser sujeito produtor e projetar seu espectador como simulacro no anteparo-imagem (FOSTER, 2017a) - como o usuário das casas de Eisenman, que deve ver a forma e apreender a estrutura profunda. É um corpo que se preenche, autônomo no sentido de dar suas 
próprias leis. O espectador como corpo social é removido da relação com o simbólico da arquitetura tornando-se abjeto no sentido apontado por Foster:

[...] abjeto é aquilo de que devo me livrar para me tornar um eu [...] uma substância fantasmática não só estranha ao sujeito, mas também íntima dele [...] o abjeto afeta a fragilidade de nossas fronteiras, a fragilidade da distinção espacial entre nosso interior e nosso exterior bem como a da passagem temporal entre o corpo materno (mais uma vez, o domínio privilegiado do abjeto) e a lei paterna. Espacial e temporalmente, portanto, a abjeção é uma condição na qual a posição de sujeito é perturbada "lá, onde o sentido se esvai". (FOSTER, 2017a, p.147)

Espectador latente no projeto, a função e o usuário não integram o simbólico do projeto, mas não há como dirimir sua presença. O espectador, abstraído da possibilidade de definição, torna-se anterior à linguagem arquitetônica. Anterior em duplo sentido, tanto de que existe na história da disciplina, quanto de precedente, faz parte daquilo que dá voz, que permite a linguagem arquitetônica; como na definição inicial de Eisenman da arquitetura a partir das formas como volumes percebidos no tempo (EISENMAN, 2006; 1970), na qual, mesmo a arquitetura como campo autônomo das formas reduzindo o espectador a um olho, ele está presente como confirmador das formas e da arquitetura. ${ }^{6}$

Concomitantemente à concentração do sujeito, do produtor, no anteparo pela produção de imagens, ocorre ação no usuário, o outro, desamparado ao ser livre da predicação da instituição. Nessa condição, afastado de uma estrutura que o predica, pode haver embate do espectador com a matéria, pode ressoar aquilo que Ihe é íntimo, mas heterogêneo, pode ocorrer evento ${ }^{7}$. Tal embate permite ao usuário realizar trabalho de significação distante da força reificadora do sistema produtor, uma vez que este sistema está circunscrito na instituição, na relação entre anteparo e produtor. A arquitetura autorreferente de Eisenman compromete o produtor, a instituição, mas deixa o espectador livre, que se torna um sujeito

\footnotetext{
${ }^{6}$ A questão da anterioridade que permite o discurso presente no abjeto aproxima-se do conceito de Khôra discutido por Derrida (1995). Ambos identificam o "materno" como quem dá a voz e é suprimido pela presença da lei "paterna", por exemplo. Conexão profícua visto a proximidade entre Derrida e Eisenman discutindo Khôra (EISENMAN, 1990; DERRIDA, 1990).

${ }^{7}$ Uma das fontes da qual emerge o conceito de evento para Safatle é sua discussão por Derrida. A proximidade entre Eisenman e Derrida (vide nota 6) possibilita a aproximação do conceito como utilizado por Safatle à discussão sobre o arquiteto.
} 
marcado por negatividade, por não pertencer, desamparado (SAFATLE, 2016). A racionalidade e as formas de possuir (medir, contar) ficam inscritas no processo de produção. Espectador frente ao projeto é repetição de outro caráter, não melancólico, mas repetição de sujeito indefinido, repetição impossível de reiterar o mesmo. Linguagem que se refaz, não há predicado do espectador para controlar essa repetição. Uma brecha, o usuário fica livre frente ao objeto, permitindo identificar nele algo além da posse.

\section{CONCLUSÃO: UMA POSSIBILIDADE DO DESAMPARO}

Formalmente, desenvolvemos leitura análoga ao processo de projeto de Eisenman. No Cannaregio, o arquiteto repete instâncias de sua House Xla em diferentes tamanhos sobre a malha. Operação analógica, processo que, pela repetição e aproximação desses diferentes, busca emergir novas questões. Aqui, repetimos e justapomos Foster e Hays, com os quais exploramos no início da carreira de Eisenman uma face do arquiteto como produtor de imagens, incluindo uma crítica a esta: ao incorporar a lógica da produção à reprodução de si - enquanto se (re)produz pela forma da produção de massa e reifica-se como mercadoria -, acusa indiretamente a estrutura do social, a colonização de esferas pela lógica do capital, característica do terceiro estágio do capitalismo. A arquitetura de Eisenman acaba por operar, ser projetada, como uma máquina de imagens.

Eisenman, então, não é extemporâneo, caminha conforme um período compreendido a partir de Jameson como momento de formação do pós-moderno. Reconhecemos que Eisenman não atesta uma condição global, mas de um tempo e local específicos: uma formação dos EUA na década de 1960. As sociedades às quais Eisenman remete, seja a europeia, seja a americana, são restritas; no Brasil, por exemplo, há outra formação. Se Eisenman gera uma despossessão do sujeito espectador, a qual pode dar condições a uma expressão do universal, esta mesma condição pode ocorrer em correntes em desenvolvimento na América Latina ou em outros lugares a partir de outras premissas, que não guardam a relação aqui vista 
com a abstração moderna. Operações sincrônicas, em diferentes locais, desenvolvem contingências distintas, mas podem ressoar.

É de um recorte, de contingências das condições de releituras e continuidades ao moderno, que emerge o processo de Eisenman reinscrever a abstração, antes no âmbito da forma, agora no sujeito espectador. A exposição no MoMA em 1988 dedicada à Arquitetura Desconstrutivista (com projetos de Frank Gehry, Daniel Libeskind, Rem Koolhaas, Eisenman, Zaha Hadid, do grupo Coop Himmelblau e de Bernard Tschumi) é exemplo de sua influência. Essa situa Eisenman como uma figura formadora ao lado de Gehry, e que forma uma nova sensibilidade ao abrir para a experiência do espaço desconstruído, ao formatar meios de apreciação de espaços fragmentados. Mas se encontramos neste conjunto aproximações ao modo como Eisenman atua, como Tschumi, há também divergências: Koolhaas por exemplo, cujos projetos partem de diagramas do programa, diferentes dos diagramas da forma de Eisenman. Processo de Koolhaas sugere uma relação diferente da aqui vista com a função, uma vez que o usuário, através do programa, é inserido desde o início. A função não seria colocada para além do anteparoimagem, mas participa da formulação do simbólico. Isso não diminui a abertura identificada na arquitetura de Eisenman, porém restringe o aqui observado a um conjunto da arquitetura contemporânea. Na década de 1960, há outros possíveis caminhos para acompanhar questão similar da autonomia e da abstração: Rossi com sua autonomia da arquitetura a partir da relação entre formas históricas constantes, os tipos, sobre uma sociedade mutante, os fatti urbani, ou Hejduk e suas paredes e máscaras.

A linguagem, o simbólico, operada por Eisenman, forma objeto que incorpora uma contradição. Hays identifica o projeto de Eisenman como prenhe de uma contradição centrada na instituição, atesta a incerteza do campo e sua verve de produzir imagens: ao edificar ocorre "[...] a funcionalização de um diagrama disfuncional e a estetização do signo conceitual" (HAYS, 2010, p.86, tradução nossa). Identificamos uma contradição diferente, na qual o apontado por Hays amplia uma face, a do reforço do anteparo-imagem, da fragmentação do objeto. Essa face leva a centralizar, a segurar a forma, a produzir imagens, o que abre para a cooptação do projeto pelo capital, ao 
processo de projeto mimetizando os meios de produção, ao distanciamento do real em direção ao simulacro, imagem-mercadoria. O outro lado dessa contradição é que acaba por liberar o espectador, torna o usuário não predicado pelo projeto, despossuído, desamparado. Uma desestruturação da relação entre produção arquitetônica e usuário. A não definição do usuário pelo projeto dificulta a ação do capital financeiro por meio da arquitetura, pela função, no espectador.

A fragmentação da cidade auxilia a perceber a estrutura de desamparo. A perda da unidade orgânica da cidade moderna é vivenciada no projeto como repetição melancólica. A partir do diagrama do olhar de Lacan, vemos a produção arquitetônica colocando-se frente ao real com simbólico desestabilizado, o que antes compunha um todo orgânico, agora é cindido. A repetição, a autorreferência, reforça o anteparo-imagem, cobre com imagens esse real, de outra forma traumático, mas abstrai o espectador. Este, não predicado, está livre para experimentar o espaço de forma performática, para o evento. A abstração, retomada à luz do presente, permite a abertura à contingência, ao, até então, impredicável, ao que não está determinado pela estrutura simbólica. Como uma estrutura tende a operar apenas em seus termos, é a possibilidade de inscrição de algo externo, contingente, que permite a formulação de algo diferente, não uma transferência, mas transformação. Se, como Jameson aponta, a imagem está em sua superficialidade associada ao capital, há uma profundidade no espaço produzido fora desta definição. Há, então, um potencial revolucionário nesta relação de disjunção, de desamparo do sujeito que se coloca frente ao projeto, há uma abertura.

Contraditoriamente, ao assumir a forma do capital financeiro, a arquitetura passa a operar segundo este, mas ao desamparar o usuário permite um vislumbre revolucionário que pode colocar em questão o sistema capitalista. Não é um diagnóstico ingenuamente otimista (apesar de este não ter sido espaço para explorar a condição do produtor), pois algumas características encontradas, como o caráter melancólico da repetição, indicam movimento de autodefesa. Ao fechar-se na autorreferência, busca preservar uma condição de individuação, de autoridade paterna do traço moderno, do traço que desenha o social, traço que se desfaz junto à perda da unidade orgânica na década de 1960, traço que tem sobrevida nas marcas de 
Eisenman. O produtor alinha-se ao capital num movimento autodestrutivo procurando preservar uma condição de potência em derrocada (SAFATLE, 2020). Ademais, pudemos observar que parte da produção contemporânea está sob premissas que a tornam incapaz de dar voz ao corpo social; corpo intricado de questões, de tensões de identidade, de reconhecimento. Talvez esta resposta seja o mínimo: se o projeto oriundo de uma história da arquitetura que negligenciou vozes e determinou corpos hoje não os consegue incorporar, deve ao menos não os silenciar, não os predicar. Espectador desamparado, não predicado, obtém brecha para um trabalho seu de significação imprevisível frente ao projeto.

\section{REFERÊNCIAS}

ARANTES, Otilia B. F. O lugar da arquitetura depois dos modernos. São Paulo: Edusp; 1993.

ARGAN, Giulio C. História da Arte como História da Cidade. São Paulo: Martins Fontes; 2014.

BURGER, Peter. Teoria da Vanguarda. São Paulo: Cosac Naify; 2008.

DAVIDSON, Cynthia. The Absence of the Presence; or, The Void. In: DAVIDSON, Cynthia (org.). Tracing Eisenman. Nova York: Rizzolli International Publications, Inc.; 2006b, p.25-31.

DERRIDA, Jacques. Khôra. Campinas: Papirus; 1995.

DERRIDA, Jacques; HANEL, Hilary P. A Letter to Peter Eisenman. Assemblage, [s.I.], n.12, p.6-13, ago. 1990.

EISENMAN, Peter. Aspects of Modernism: Maison Dom-ino and the Self-Referential Sign. Log, Nova York, n.30, 2014, p.139-151.

. The Formal Basis of Modern Architecture. Zurich: Lars Muller Publishers; 2006.

. Notes on Conceptual Architecture. In: EISENMAN, Peter. Eisenman Inside Out. Yale University Press; 2004. p.10-27.

. Diagram Diaries. [S.I.]: Universe Publishing; 1999.

. The End of the Classical: The End of the Beginning, the End of the End. In: NESBITT, Kater (org.). Theorizing a New Agenda for Architecture. Nova York: Princeton Architectural Press; 1996, p.211-227. 
. Post/El Cards: A Reply to Jacques Derrida. Assemblage, [s.I.], n.12, p.14-17, ago. 1990.

. House X. [s.I.]: Rizzolli; 1982.

. House I. In: EISENMAN, Peter et al. Five Architects: Eisenman, Graves, Gwathmey, Hejduk, Meier. [S.I.]: Oxford University Press; 1975, p.15-23.

. From Object to Relationship II: Casa Giuliani Frigerio: Giuseppe Terragni Casa del Fascio. Perspecta, New Haven, v.13/14, p.36-65, 1971.

. Dall'Oggetto alla Relazionalità: la Casa del Fascio di Terragni. Casabella, Milão, n.344, p.38-41, 1970.

EVANS, Robin. Not to be used for wrapping purposes. Peter Eisenman: Fin d'Ou T Hou

S. in AA Files, Londres, n.10, p.68-78, 1985.

FOSTER, Hal. O Retorno do Real. São Paulo: Ubu Editora; 2017a.

. O Complexo Arte-Arquitetura. São Paulo: Ubu Editora; 2017b.

HAYS, Michael. Architecture's Desire. Cambridge: MIT Press; 2010.

IZAR, Gabriela. Diagramática: descrição e criação das formas na arquitetura seriada de Peter Eisenman. Tese (Doutorado) - Curso de Arquitetura e Urbanismo, Universidade de São Paulo, São Paulo; 2015.

JAMESON, Fredric. Periodizando os anos 60. In: HOLLANDA, Heloisa Buarque de (Org.). Pós-Modernismo e Política. Rio de Janeiro: Rocco; 1992, p.81-126.

. Pós-Modernismo: a Lógica Cultural do Capitalismo Tardio. São Paulo: Ática; 1996.

JENCKS, Charles. Arquitetura Internacional: Últimas tendências. [s.l.]: Gustavo Gili Editorial S.A.; 1989.

JOHNSON, Philip; WIGLEY, Mark. Deconstructivist architecture: Catálogo de exposição. [s.I.]: MoMA; 1988.

KIPNIS, Jeffrey. Twisting the Separatrix. In: HAYS, Michael (org.). Architecture Theory Since 1968. Cambridge: MIT Press; 1998, p.710-742.

MENTONE, Bruno. A House I de Peter Eisenman, Entre as Bases Formais da Arquitetura e a Arquitetura Conceitual. Dissertação (mestrado) - Curso de Arquitetura e Urbanismo, Universidade de São Paulo, São Paulo; 2020.

MONEO, Rafael. Inquietação Teórica e Estratégia Projetual. São Paulo: Cosac Naify; 2008.

MONTANER, Josep Maria. Depois do Movimento Moderno: Arquitetura da Segunda Metade do Século XX. [s.I.]: Gustavo Gili; 2001. 
ROWE, Colin. Introduction. In: EISENMAN, Peter et al. Five Architects: Eisenman, Graves, Gwathmey, Hejduk, Meier. [S.I.]: Oxford University Press; 1975, p.3-7.

SAFATLE, Vladimir. O Circuito dos Afetos: Corpos Políticos, Desamparo e o Fim do Indivíduo. Belo Horizonte: Autêntica Editora; 2016.

. Para Além da Necropolítica. Disponível em: <https://www.n1edicoes.org/textos/191>. Acesso em: 18 out. 2020. 